\title{
Population of Russia: What Can We Expect in the Future?
}

\author{
EVGENI ANDREEV \\ Institute of Statistics and Economic Studies, Moscow, Russia \\ and \\ SERGEI SCHERBOV and FRANS WILLEKENS* \\ University of Groningen, Groningen, The Netherlands
}

\begin{abstract}
Summary. - The paper presents the first ever demographic scenarios for the regions of Russia. Scenarios are developed for 49 oblasts (regions), six krays (territories), 21 republics, one autonomous oblast and two national cities, Moscow and St. Petersburg. Five scenarios are considered: two optimistic scenarios, two medium scenarios and one pessimistic scenario. The scenarios are combinations of three mortality scenarios, two fertility scenarios and three migration scenarios. Results and a discussion of the differences between the scenarios are presented for 11 economic-geographic regions. The main findings of the scenario analysis are: (a) the population decline, which started in 1992, continues in all scenarios; (b) aging of the population reaches unprecedented levels; and (c) the spatial redistribution of the population out of Siberia to the European part of Russia, in particular the southern regions (North Caucasus and the Volga Region), continues. (C) 1998 Elsevier Science Ltd. All rights reserved.
\end{abstract}

\section{INTRODUCTION}

From an analysis of recent demographic changes in Russia, the following general trends emerge':

(a) Increasing mortality since the $1960 \mathrm{~s}$, with a brief period of mortality decline in the second half of the $1980 \mathrm{~s}$ and a rapid increase in the 1990s;

(b) Relatively stable fertility around two children per woman for many years, a sharp decline in fertility in the first half of the $1990 \mathrm{~s}$;

(c) Decrease in internal migration in the early 1990s with a slight recovery in 1994 and a continued recovery in 1995. Two characteristic patterns are observed: (i) outmigration from urban areas in the early 1990s for a few years followed by a slight reversal of the trend (urban population starts growing again), and (ii) substantial migration from the North and the Far East to the European part of Russia, in particular its southern part, and to Ukraine.

(d) Continued outmigration from former republics in Central Asia and the Caucasus.

In this paper, we look into the future. Based on the study of historical and recent trends and on expert opinions about what changes may occur, scenarios are developed that present realistic and internally consistent views on what the future may look like. These scenarios are not forecasts, i.e. they do not represent the most likely future. They represent possible futures based on extensive analysis of trends and changes that may be expected on theoretical grounds. Disaster scenarios that may result from natural or man-made catastrophes are omitted because an objective assessment of the demographic consequences is beyond the scope of the current investigation. It is expected, however, that mortality will increase, fertility may decline further (at least for a period) and the level and direction of migration will depend on the nature

* This report is an outcome of a cooperation between the Population Research Centre, University of Groningen, and the Department of Demography, Institute of Statistics and Economic Studies (ISES), State Committee of the Russian Federation on Statistics, Moscow. It is part of the project "Demographic prospects of Russia," funded in part by INTAS (International Association for the Promotion of Cooperation with Scientists from the Independent States of the Former Soviet Union), an association funded by the European Commission in Brussels and the member countries of the European Union (project No. INTAS93-1732) 
and location of the disaster. For instance, the war in Chechen resulted in a mass flow of refugees and forced migrants from Chechen and Ingush republics, even before the open contlict started (Andreev, forthcoming).

This report presents demographic scenarios for Russia and its regions. The base population is the resident (de jure) population on January 1 , 1995 (Goskomstat estimates). The Russian Federation consists of 89 administrative divisions. Most of the regions have an administrative function only; these are the 49 oblasts (region), the six krays (territories) and the two national cities Moscow and St. Petersburg. Since the word "region" is generally used for oblast, we use "areas" to denote any of the administrative areas. Some areas have some degree of autonomy. Three types of autonomous areas exist. First, the 21 republics that were established in the 1920 s by Lenin to give some autonomy to large minority populations ${ }^{2}$ and that, up to 1994 , were called "autonomous republics." The largest republics are Tatarstan (population of 3.8 million in 1995), Dagestan (two million), Chechen (904,000), and Bashkortostan (four million). For small ethnicities, the autonomous area is called an autonomous oblast. On January 1, 1994 there was one autonomous oblast, the Jewish autonomous oblast in the Far East $(210,000,4.2 \%$ Jewish in the 1989 Census). For very small ethnicities, the autonomous area is called autonomous okrug (district) (A.D.) and is generally part of an oblast or kray. There are 10 autonomous districts, nine are part of an oblast or kray and one (Chukchi autonomous okrug) is a separate entity not part of an oblast or kray. The administrative units are combined into 11 larger economic-geographic regions. These regions have no administrative function. The economicgeographic regions are the same as those shown in the Demographic Yearbook (Goskomstat of Russia, 1996). Scenarios are developed for 79 areas. Autonomous oknugs that are part of an oblast or kray are included in the oblast or kray.

The structure of the paper is as follows. Section 2 presents a brief history of population projection in Russia. The possible trends in mortality, fertility and migration, i.e. the scenarios, are presented in Section 3. The general approach to scenario setting was first to consider possible development at the national level and then to differentiate developments at the regional level. The regional scenarios that result are expressed as deviations from what we may assume at the national level. Section 4 describes what the possible trends in demographic parameters mean for the aging of the population, the sex ratio and the spatial redistribution. We identify regions of growth and areas of decline, and quantify the extent of aging in Russia and its regional differences. Results are presented for the country as a whole and for economic-geographic regions which are aggregations of oblasts and krays. We look into the future, up to the year 2025. Because of the demographic inertia, some of the consequences of the demographic changes that occurred in the recent past or that are occurring today will only become manifest at the level of the population in the next century. By limiting the horizon to 2025 (30 years from now), some consequences that reach their fullest extent later escape our view. It was decided not to look beyond 2025, however, to express the prevailing uncertainty about the long run. The projections were prepared using the computer program DIALOG, developed by Scherbov. A description of the model may be found in Andreev et al. (1997).

\section{BRIEF HISTORY OF PROJECTIONS IN RUSSIA}

The first official forecast of Russia's population was performed in 1922 at the RSFSR Gosplan under the supervision of E.M. Tarasov and S.G. Strumilin. Its methodology was primitive, its statistical base was unreliable, and five years later this forecast essentially came into conflict with the real population dynamics. Then followed a long period when the available information was so scant and unreliable that any serious forecasting was impossible and all attempts at prediction were unsuccessful.

After the Population Census of 1959, forecasts of the population became regular and the component method came into practice. Prior to the USSR disintegration, population forecasts for the Russian Federation were obtained within the frames of a general forecast of the country's (USSR) population. Projections of the RSFSR republic (Russia) were made for urban settlements and rural areas. No further geographical detail was considered. The population numbers for separate areas (oblasts, autonomous republics, and territories) were derived from the population by allocating the projected population to the various regions. With this method, the sum of the subnational forecasts coincides with the given forecast for Russia as a whole. A projection method that allocates the national population to subnational areas does not take into account the differences in fertility and mortality that may exist at the regional level.

Migration forecasts were constructed by 
Gosplan and other agencies, which were involved in planning the economy. In general, the migration forecasts were derived from desired manpower flows. Such forecasts did not adequately account for established migration flows, and this was the principal source of forecasting errors.

Prior to 1991, in the USSR, the official population forecasts used by the Government and other state agencies were carried out jointly by the Union Goskomstat and Gosplan, for all the Union Republics, and by the RSFSR Goskomstat and Gosplan for Russia's regions. These forecasts were systematically refined and re-calculated but remained unpublished and were meant solely for internal use; the government forbid publication of any other forecasts. In 1991 the first statistical report containing projections was prepared; it also remained unpublished because of the disintegration of the USSR.

During 1991-95 official forecasts were calculated jointly by the Goskomstat of Russia and the Centre of Economic Conjuncture (CEC) of the Government of the Russian Federation; the CFC emerged from the computer center of Gosplan (see, c.g., Centre for Economic Conjuncture, 1994). Since 1996, official projections have been prepared by Goskomstat; to that end, a new unit has been established. The calculation methodology was formulated in the 196() Forecasting assumptions are formulated in terms of changes in age-specific rates of mortality and fertility (ratios of rates). Migration perspectives are estimated using net migration by area for each year of the forecasting period.

\section{THE SCENARIOS}

\section{(a) Introduction}

Scenario analysis consists of two parts. First is the formulation of hypotheses about possible trends in mortality, fertility, internal migration, and external migration, and second is the assessment of the impact of the possible changes in the demographic processes on the level, age-scx composition and spatial distribution of the population.

(i) Scenario setting. The hypotheses about the demographic processes constitute the basic scenarios. Although initially scenarios may be formulated in terms of general descriptions of what we may assume, ultimately they need to be translated into specific values of the parameters that characterize mortality, fertility and migration. These parameters are the age-specific rates by sex, area and period. Nationality is not considered in this report, although persons of different nationalities may have different demographic behavior. To reduce the number of parameters that must be given values as part of the scenario setting, a number of simplifying assumptions are made. First, it is assumed that a change in mortality, fertility or migration is mainly a change in the level and that the age profile does not change (fertility, migration) or changes in a limited way (mortality). This simplification is common in demographic scenario setting and is also realistic unless major shifts in demographic behavior are expected. This assumption leads to the following scenario variables. Fertility scenarios are expressed in terms of number of children per woman (Total Fertility Rate, TFR). Mortality scenarios are in terms of the life expectancy at birth. Changes in the mortality profile are allowed to account for divergent changes in infant and adult mortality. External migration scenarios are formulated in terms of number of migrants. Second, it is assumed that areas with similar past demographic trends will experience similar changes in the future. Clusters of areas are thereby identified with comparable patterns of change.

(ii) Impact assessment. In order to assess the impact of possible changes in the demographic processes on the level, age-sex composition and spatial distribution of the population, we used a projection model. The parameters of the model represent the basic features of the mortality, fertility and migration processes. Their values are determined by the scenario setting, except for the base period. The model describes how mortality, fertility and migration processes combine to produce population changes. The projection model used in this paper allows for both internal and external migration and enhances scenario setting. Age is measured in five-year age groups. Consequently, the projection interval is five years too. The base population used for the scenarios is the population on January $1,1995$.

The scenarios for the areas are derived in two steps. First, national scenarios are formulated and second, these scenarios are regionalized. 


\section{(b) The scenarios: summary}

A total of five scenarios are reportcd in this study. They are combinations of assumptions about future trends in mortality, fertility and migration. Three letters identify each scenario. The first denotes the assumption about mortality and fertility; the second refers to external migration; and the third to internal migration. Threc combinations of mortality-fertility trends are considered. They are labeled "optimistic," "pessimistic" and "medium":

"Optimistic" (O): mortality declines and fertility increases

"Pessimistic" (P): mortality increases and fertility continues to decline

"Medium" (M): mortality decline starts later (in next decade) and is slower than in the "optimistic" scenario; fertility remains more or less at its current level

Two external migration scenarios are considered. Both refer to the migration between Russia and the other states of the former Soviet Union. Migration across the borders of the former Soviet Union is assumed to be the same for both scenarios. The two scenarios differ in terms of the level of emigration from Russia to the former Soviet republics. The level of immigration from the former republics to Russia is the same for both scenarios. The external migration scenarios are:

"High" $(\mathrm{H})$ : relatively high net migration to Russia due to a relatively low cmigration from Russia to the other former Soviet republics

"Low" (L): relatively low net migration to Russia due to a relatively high emigration from Russia to the other former Sovict republics

Three internal migration scenarios are considered:

Stable mobility (A): migration rates are almost the same as in 1994

High mobility (C): internal migration rates increase, starting in the year 2000 , to reach in $20202025150 \%$ of the level in 1994. At the same time, regional differences in migration rates decline. Mass outmigration from East and North regions stops. Beginning in 2005, immigration to these regions begins to compensate for the high outmigration and the population decline that occurred in the period after 1992. Migration patterns of industrial centers are such that the population does not decline.

Medium (B): average of $\mathrm{A}$ and $\mathrm{C}$

Five scenarios are produced:

- Two optimistic scenarios with low external migration: OLC (high mobility) and OLB (medium mobility)

- Two medium scenarios with high external migration: MHC (high mobility) and MHB (medium mobility)

- One pessimistic scenario with high external migration and stable mobility: PHA

In the following, we look at the scenarios in some more detail.

\section{(c) National scenarios}

\section{(i) Mortality}

The mortality scenarios are based on the analysis by Andreev (forthcoming). For a detailed description of the mortality outlook, the reader is referred to that publication. The scenario variable to describe the mortality trend is the life expectancy at birth $[\mathrm{e}(0)]$. In the pessimistic scenario, it is assumed that the stagnation in the economic sphere continues. Life expectancy continues to decline following the trend of the past 30 years (since 1965). The optimistic scenario assumes a relatively rapid end of the crisis. Mortality is assumed to decrease at a rate that was typical for West Europe in the 1950s-1960s. United Nations assumed a similar rate of mortality decline in their projections for countries in transition.

To translatc changes in life expectancy at birth $[\mathfrak{e}(0)]$ into changes in age-specific rates of death, we used the Brass logit model with one paramcter (intercept). The intercept is derived from e(0) by an iterative proceduret; the slope of the regression equation is assumed to remain constant at one.

A special feature of mortality in Russia is the large difference between male and female life expectancy. In 1996, the difference was about 12.7 years $[\mathrm{e}(0)$ was 59.8 for males and 72.5 for females]. In some areas the difference is 14.5 years (e.g., Novgorod oblast). No explicit assumption is made about the increase or decrease of the difference. The results of the scenarios show that the difference at the end of projection horizon is 17 years in the pessimistic scenario and 10 years in the optimistic scenario.

\section{(ii) Fertility}

The fertility scenarios are based on the analysis by Bondarskaya and Darsky (forthcoming). For a detailed description of the fertility outlook, the reader is referred to that paper. The fertility scenarios were prepared for this report by Bondarskaya and K'arkhova of the 
Department of Demography, ISES. In order to determine the fertility scenarios, the following information was used: fertility trends from vital statistics; two indicators of the Micro-Census of February 1994: expected number of children for youngest cohorts $(18-29)$ and completed fertility of all cohorts (18-44); and illegitimate births from the vital statistics.

In the pessimistic scenario, the socioeconomic crisis continues and the TFR continues to decline and stabilizes at a very low level. It is assumed that fertility tends to a minimum level, below which it cannot fall. The minimum level TFR is 0.8 for urban areas and 1.2 for rural areas. Some rural areas have already a TFR of around 1.2. For these areas, it is assumed that fertility increases slightly in the future. It is further assumed that regional fertility differences will decline, i.e. Russia becomes more homogeneous with respect to the reproductive behavior of the families.

In the optimistic scenario, it is assumed that the fertility decline in past years is entirely due to postponed births. Therefore, we may expect fertility to increase at the end of the crisis. Fertility is assumed to first increase relatively rapidly from its level of 1.4 in 1994 (due to postponed births) and to stabilize at a TFR of 1.9 in 2020-2025. This scenario is based on the Micro-Census: it is assumed that by the year 2000 , the TFR will reach a level that is equal to the average expected number of children for all cohorts (women aged 18-44 at time of MicroCensus). In other words, the maximum completed fertility of young cohorts will be the same as the expected fertility of all cohorts in the 1994 Micro-Census.

In the medium variant, it is assumed that in 2000-2005 economic crises will come to an end. The end of the crises will allow families to implement their reproductive intentions more fully. Under these assumptions the future TFR value in the year 2000 is taken approximately at the level of expected number of children for young (below age 30) cohorts of women in the 1994 Micro-Census. Under that assumption, TFR in 2000 will be 1.38 for urban women and 1.84 for rural women. The TFR values for the years 2005 and 2015 are based on the average expected number of children for the cohorts of women who at the time of Micro-Census were 20-24 years old (for 2005 TFR) and 18-19 years old (for 2015 TFR).

\section{(iii) External migration}

The external migration assumptions focus on the migration between the former republics and
Russia. Migration from China, Korea and Africa to Russia is not considered. That migration is a political issue, and a scenario is difficult to formulate. Labor migration from Russia to Europe and the United States is not considered either. As far as the migration from Russia to outside the former USSR is concerned, it is assumed that migration keeps the character of ethnic migration. We expect the number of emigrants to decline from 100,000 to $65,000-70,000$ by 2025 . Part of that decline is duc to the decreasing level of emigration of Jews and Germans; the emigration will be complete by 2005 .

Migration from former Soviet republics to Russia is considered to remain largely repatriation. Return migration is currently going on for all republics, cxcept for Ukraine and Byclorussia. We expect that the trend continues in the future (assuming no disasters!). Two types of assumptions are made:

- the rates at which Russians leave the former republics will be same as in 1993-94;

- the proportion of Russians among immigrants will be same as in 1993-94 $(65 \%)$, excluding Ukraine and Byelorussia.

We made the following assumption about the number of immigrants: number of Russians in former republies in 1994 times emigration rates. The total number of migrants from other former republics to Russia depends on number of Russians. That seems realistic since the majority of migrants will be Russians or members of Russian families.

Today, there is very little migration out of Russia (in 1994 the migration efficiency ${ }^{5}$ is $48 \%$; most migration is repatriation). When this repatriation is over, the migration efficiency is expected to decline to $8 \%$, which is comparable to the level in 1989, i.e. before the dissolution of the USSR (1991). In the HIGH scenario, the efficiency will remain at $48 \%$ and in the $L O W$ scenario, it will change linearly from the current value of $48 \%$ to $8 \%$.

\section{(d) Regionalization}

\section{(i) Mortality}

In order to determine the regional mortality scenarios, we compared the mortality trends in Russia and the regions. The trend was investigated separately for children (0) 4) and adults using the life tables for the areas (oblasts/kray). Particular attention was devoted to the infant mortality (IMR) and the life expectancy at age 1 
[e(1)]. These indicators for Russia and the areas were compared. Two situations were distinguished: the trend in the area is comparable to the trend in Russia; and the regional trend differs considerably from the national trend. In the first situation, the mortality trend for Russia as a whole was used but the IMR and e(1) were substituted for the regional values. The value in 2025 was determined assuming parallel development with Russia. Rural-urban differences were taken into account (life tables were calculated for rural and urban areas). The results were aggregated to the level of economic-geographic region to prepare the scenarios. In case of regional peculiarities, two cases were distinguished.

- If there was no recent increase in mortality, we assume mortality to be stable during the entirc projection horizon (to 2025 ) in the pessimistic scenario; in the optimistic scenario, mortality is assumed to decline parallel to the decline in Russia (this case applies to rural areas of some republics of North Caucasus).

- In case no real dynamics were observed we ignore regional dynamics and assume that the mortality trend of neighboring regions applies (this is the case of Magadan, Chucki, Kamchatka, and a few other areas).

In total, not more than 10 areas were identified as having peculiarities in their mortality trend.

\section{(ii) Fertility}

One could expect a more rapid decline in fertility in areas with high illegitimate fertility, since they are further in the Second Demographic Transition (the North and Far East Regions: Perm, Magadan, Kamchatka, Irkutsk oblast, Buryatia and Komi republics). In these areas, fertility decline will be more rapid and trend inversions are less likely. The trend in TFR was derived from age-specific fertility rates, which are calculated annually using the numbers of births from the vital statistics and estimates of the female population. The estimates are based on the census population and vital events in years following the census.

\section{(iii) Migration}

In the first internal migration scenario (A), the level of migration and the direction (destination probabilities) are considered to remain stable. The migration matrix for 1994 was used for both sexes combined and all ages combined. The probability of moving from one area to another area within five years must be determined because the projection is in five-year intervals. The five-year probability was determined by raising the one-year migration probability matrix to the power five. The denominator was the number of residents in an area on January 1, 1994. To obtain the number of migrations during 1995-99, we multiplied the population on January 1,1995 by the migration probability. Analogously, the number of migrants for each five-year period during 1995-2025 was obtained. During simulation, this procedure resulted in a negative population for one area (Magadan). This area experienced a major outmigration in 1994. To avoid a negative population, outmigration was assumed to be less than observed in 1994.

In the second internal migration scenario (C) mobility is assumed to increase, starting in the year 2000 . The general mobility level, expressed as the probability of departure from each area, is increased by $50 \%$ to obtain the probability in 2020-2024. The basis for this assumption is that the current mobility level is very low and a $50 \%$ increase would yield a mobility level that is comparable to the level before 1989. Because the current rate of outmigration from somc areas is very high, the assumption of a $50 \%$ increase cannot be applied to all areas. For instance, oulnigration from the North and the East is currently very high leading to a decline of the population. It is assumed that the decline is temporary and associated with the economic situation. When the economy recovers, the North and the East will also recover and probably more rapidly than some other areas in the country because of the location of resources. It is assumed, therefore, that with increasing mobility, the population decline in the North and the East is compensated by an increase in immigration from other areas of Russia. The "pull" factor is increased to reach a level of immigration that is sufficient to compensate part of the population decrease in 1992-99. In this scenario, it is further assumed that population does not move from industrial centers (Moscow, St. Petersburg, and Novgorod).

In the third internal migration scenario (B), the level and direction of migration is between (A) and (C), except for Magadan. For Magadan, the migration cannot remain at the level of 1994 $(30,000$ of the 200,000 residents left Magadan in 1994) because the area would depopulate completely.

By iteration, it was assumed that: overall migration increases by $50 \%$; losses in the East 
and the North are compensated; and there is zero net migration for industrial centers. In addition, the migration matrix should remain as close as possible to the original (1994) migration matrix. Andreev (forthcoming) compares three matrices (1989, 1992 and 1994). The matrix of 1992 was considered unrealistic (e.g., migration from large cities) and was therefore ignored.

The regionalization of external migration was integrated with the assumptions on internal migration. Expected changes in internal and external migration are combined in values of inflows and outflows.

After the regional scenarios were set, all regions were compared. If inconsistencies were discovered, the reason was investigated and the scenario adjusted.

For some areas no historical data existed because the area was established only recently. For instance, Altai Republic did not exist, but Altai territory (kray) did exist. No data exist for Adygeya Republic, Khakasia Republic, Karachaev Circassian Republic, or Jewish autonomous oblast. In these cases, expert opinions and information from territories with comparable populations were used. For instance, Tuva was selected to derive mortality scenarios for Altai.

\section{RESULTS}

\section{(a) Highlights}

The five scenarios result in five sets of population projections. Each set represents an alternative future, i.e. a trajectory based on specific assumplions about possible changes in mortality, fertility and migration. The range of alternatives represents a continuum of what we consider to be possible and it expresses the uncertaintics about the future. We do not know precisely what the future will look like, but we have a reasonable idea of what may be expected, provided the conditions do not change drastically.

The highlights of the results of the scenario analysis are:

(i) The population decline, which started in 1992, continues in all scenarios. The population of Russia reached its maximum on January 1, 1992 (148.3 million) and has declined since (147.6 in 1996), due to negative natural increase. The annual number of deaths exceeds the number of hirths hy almost one million and the difference is fast increasing $(220,000$ in $1992,750,000$ in 1993 and 893.000 in 1994). The positive migration balance, which increased from 176,000 in 1992 to 810,000 in 1994 , and then declined to 502,000 in $1995,{ }^{6}$ compensates a large part of the excess deaths over births but it cannot prevent the population from declining. Without the migration balance, which has been positive on a continuous basis since 1975 , the population growth of Russia, which in the past 20 years (1975-95) was $11 \%$, would have been $8 \%$ and the country would have had a net loss of 1.5 million people over 1992-94. The expected population decline between 1995 and 2025 ranges from two million in an optimistic scenario (OLB) to 32 million in a pessimistic scenario (PHA), i.e. a decline by more than $20 \%$ in 30 years. The pessimistic scenario does not contain anything exceptional. It assumes a continuing fertility decline (TFR declines further from its current level of 1.3 to 1.05 in 2025), consistent with the expectation expressed by women in the 1994 Micro-Census, no changes in mortality for females and a continuing increase in mortality for males (life expectancy declines further from the current level of 57.6 to 54.0 in 2025 ; the decline is much less rapid than observed in recent years ${ }^{7}$ ).

(ii) Aging of the population reaches unprecedented levels. The mean age of the population of Russia, which was 36 years in 1995, increases in all scenarios; in 2025 it reaches about 40 years in the optimistic scenario (low mortality, high fertility) and 42 years in the pessimistic scenario (high mortality, low fertility). The pattern of aging changes over time. Up to 2010, the increase in mean age is caused by the decline of children (as a result of low fertility) and an increase in population of working age (15-59). Beyond 2010, the $60+$ population rises sharply and the mean age increases accordingly. In 1995 , 22.5 million people were aged $60+$, which is $17 \%$ of the population, up from $15 \%$ in 1989. Of these elderly, two-thirds (67\%) are females and one-third are males (in $1989,69 \%$ were females). In 2025 , the number of $60+$ persons will be 28 million in the optimistic scenario (OLB), $61 \%$ of which will be females, and 22 million in the pessimistic scenario (PHA), with the female proportion at $56 \%$. The female proportion in the $60+$ population declines in all scenarios because of the 
normalization of the age structure. The low number of males $60+$ (and particularly $70+$ ) today is to be attributed to the losses during WWII. ${ }^{8}$

(iii) Associated with aging is the increase in old-age dependency ratio." In 1995, Russia had two persons of $60+$ for every seven persons of working age $(15-59)$. The ratio will not change much in the next 15 years and will even decline a little. But after 2010 , it will increase rapidly to two $60+$ for every six persons of working age in 2025 in the "pessimistic" scenario and to two $60+$ for every five persons of working age in the "optimistic" scenario. The difference is due mainly to differences in mortality.

(iv) The spatial redistribution of the population is determined largely by internal migration although regional differences in mortality and fertility are substantial." The most significant redistribution of the population takes place in the stable internal migration scenario. In the PHA scenario, the share of the population living in the Far East economicgeographic region declines from $5.2 \%$ in 1995 to $3.5 \%$ in 2025 (the number of people in that region declines from 7.6 million to 4.1 million). The decline is attributed 10 the high recent outmigration, which is assumed to continue in the future. Note that the migration from China to the Far East (most illegal) was not accounted for. Zaianchkovskaya (1994) estimated the number of Chinese in the Far East at about one million. The North, North West and East Siberia economic-geographic regions see their share decline too, but less pronounced as the Far East. The population is redistributed to the European part of Russia, which gets $80 \%$ of the population of Russia, the largest increase being in the North Caucasus and the Volga Regions. In the high mobility scenarios (OLC and MHC), the share of the Far East Region increases, although marginally. This trend is related to the assumption that, with increased mobility, some of the population losses in the Far East since 1992, are compensated for by immigration.

\section{(b) Further details}

A first result is the development of the demographic parameters at the national level.
Recall that the hypotheses that enter the scenarios were specified for each of the 79 areas (or clusters of areas). Regional differences in population dynamics change the weights the regional parameters receive in determining the parameters at the state level. Figure 1 shows the trajectory of the Total Fertility Rate (TFR) that results from the assumed trajectories at the regional level. For reference, the TFR is also given for 1980-95. For future periods, the TFR is shown for the mid-period of five-year periods (the projection interval is five years). The TFR of Russia remains below replacement level for the three fertility scenarios. Mortality changes are summarized in Figure 2. Figure 2 shows the changes in the male and female life expectancies at the national level implied in the assumed regional variations in mortality levels. The changes in the level of net migration are shown in Figure 3. For 1990-94, net migration amounted at 326,000 per year on average. Bccausc most migration is repatriation of Russians living in the other states of the former Soviet Union, net migration is expected to decline to a level of 140,000 in the HIGH scenario and to minus 25,000 in the $L O W$ scenario (i.e. a net outflow of 25,000 persons).

The impact of the various scenarios on the size of the population of Russia was highlighted above. The population numbers in Russia and each economic-geographic region for each scenario, are shown in Table 1.

The scenarios have a different impact on the age-sex composition of the population. The sex ratio of the population (number of males per 100 females) is expected to decline in all scenarios from its current level of 88 . The decline is negligible in the optimistic scenario but is large in the pessimistic scenario, associated with the assumption of relatively stable mortality for females and a continued increase in mortality for males. In the worst case, the sex ratio declines to 78 in 2025 , which implies that males constitute only $44 \%$ of the population and females $56 \%$.

Aging is an important feature of most populations of the world today. Russia is no exception. Because of the high male mortality at adult ages, however, aging is less rapid than in some other countries. The extent of aging may be summarized by the mean age of the population. The mean age increases from its current level of 36 years to close to 40 years in the optimistic scenario and more than 42 years in the pessimistic scenario. In the Central and North West Regions, the mean age is already relatively high (38) and continues to increase to more than 43 years in the pessimistic scenario. The youngest 


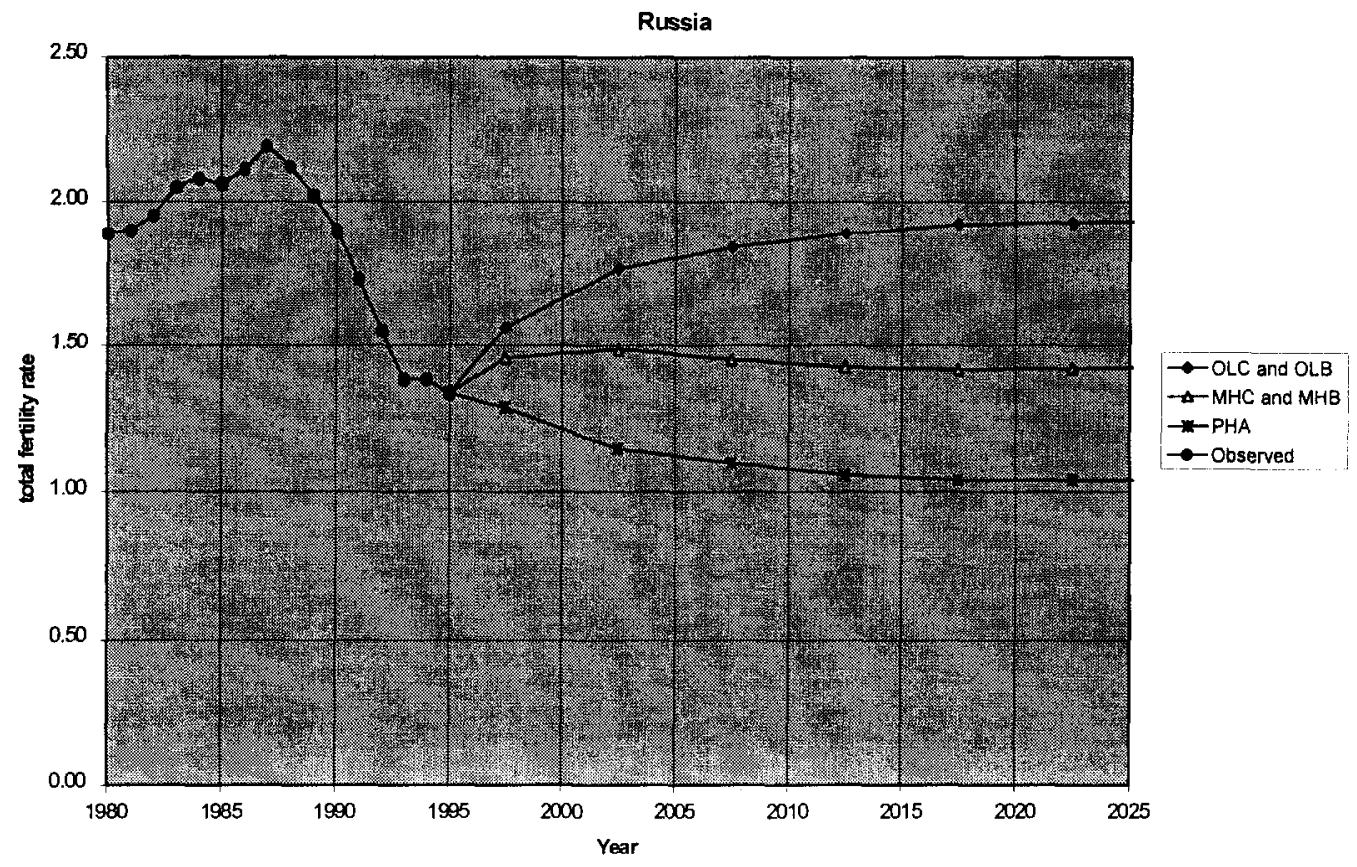

Figure 1. Total fertility rate in Russia, 1980-2025: different scenarios:

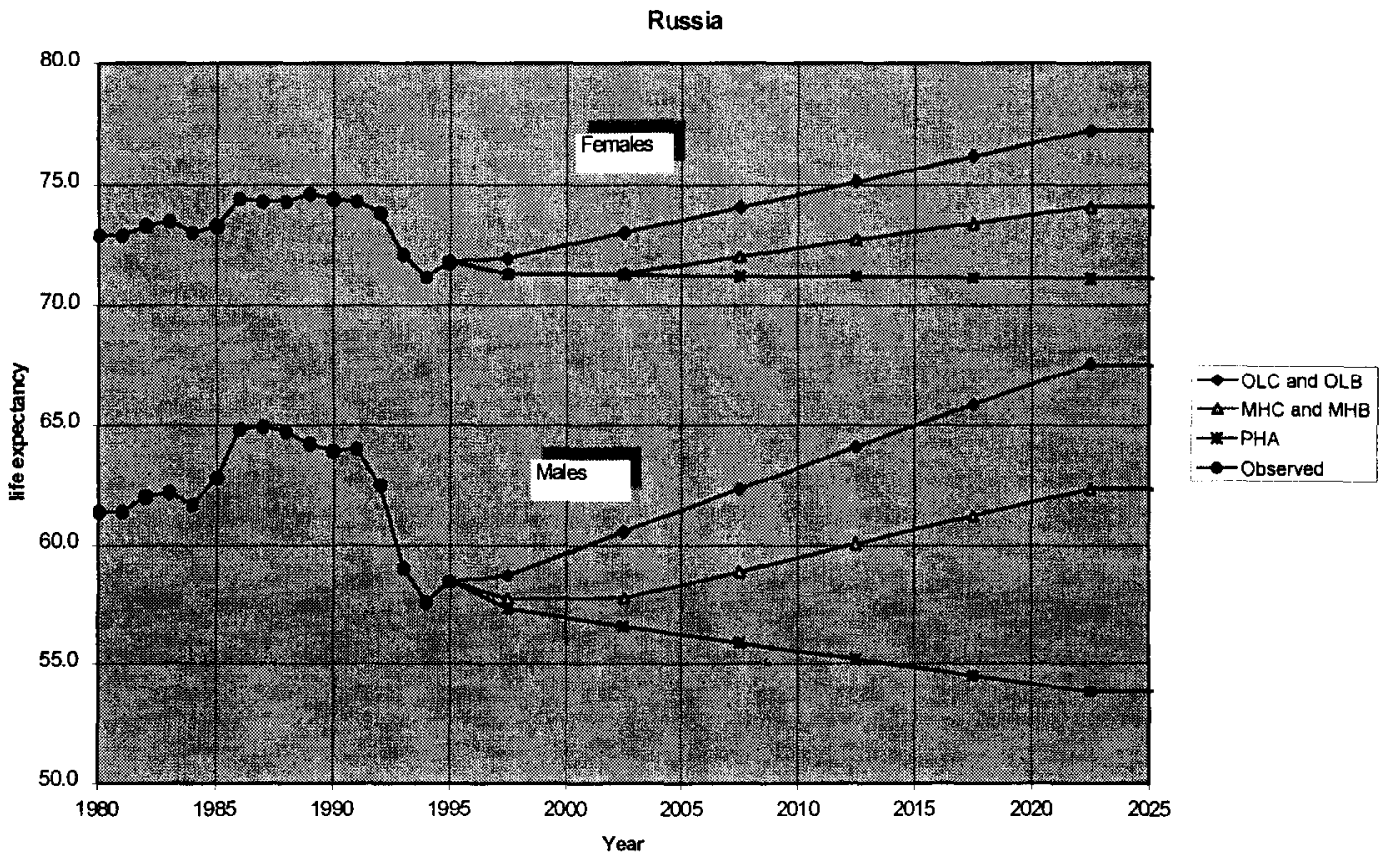

Figure 2. Life expectancy at birth in Russia, by sex, 1980-2025: different scenarios. 
The Russian Federation

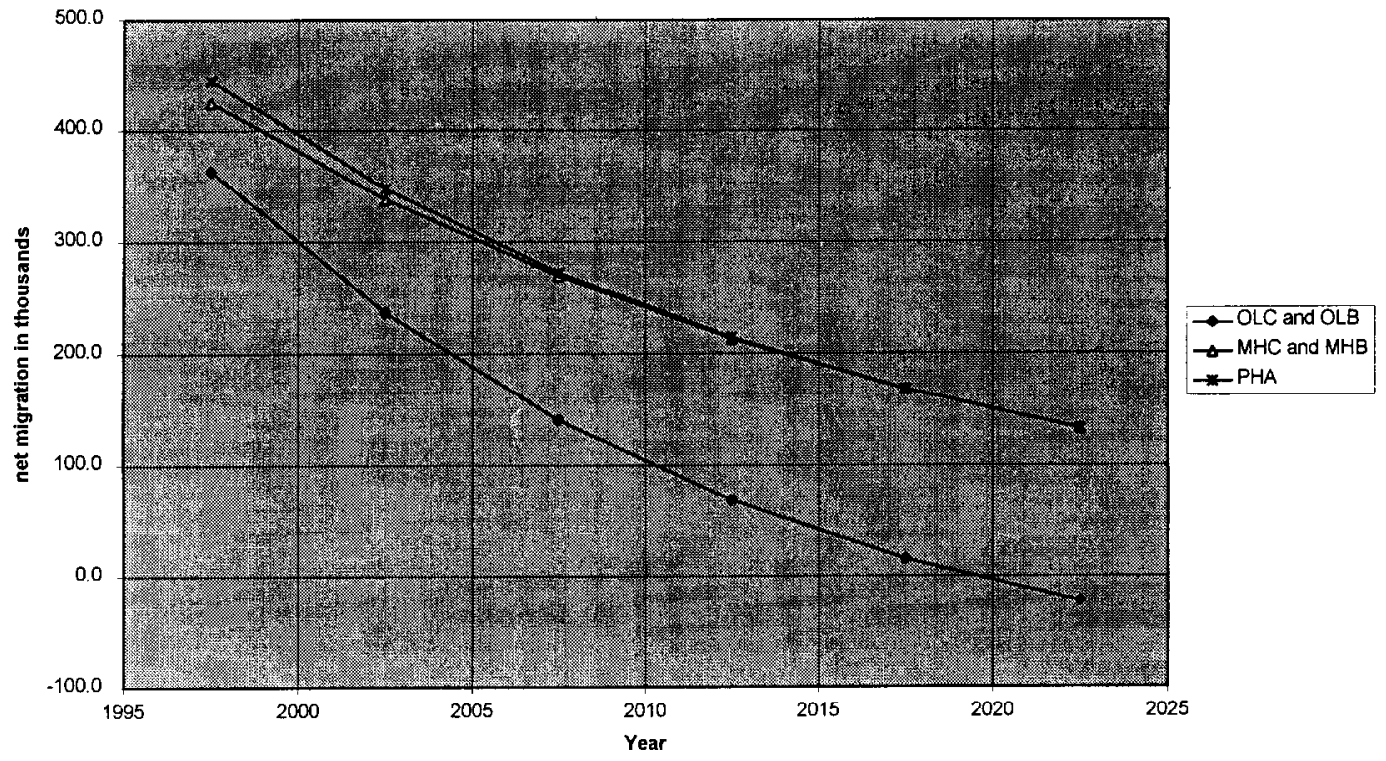

Figure 3. Level of net migration (in thousands), Russia. 1995-2025: different scenarios.

population lives in the Far East and East Siberia (mean age 33); in these regions the mean age will remain the lowest of Russia in all scenarios. Aging is least rapid in the North Caucasus Region. The mean age was 35 in 1995 , but it will not increase as fast as in the other regions. In 2025, the North Caucasus has among the youngest population of Russia (with the Far East and East Siberia). In 1995, the TFR of the region was the highest in the country (1.7) reaching levels of 2.6 in the Republic of Dagestan, which are considerably higher than the TFR in other regions, including the regions of the Far East and East Siberia (except the Republic of Tuva with a TFR of 2.5 in 1995). ${ }^{11}$ The relatively young population in the Far East and East Siberia may be attributed to the emigration of older people (at retirement due to harsh living conditions), whereas the relatively young population in the North Caucasus is due to the higher than average fertility.

A common indicator of aging is the old-age dependency ratio. The trend is consistent with the trend in the $60+$ population. In 1995 the ratio was 0.27 . It remains around that level up to 2010 and increases rapidly afterward to reach a level between 0.36 and 0.38 depending on the scenario. Whereas the turning point in the old-age dependency ratio occurs in 2010, the turning point in the total dependency ratio occurs five years earlier, in 2005 . This trend is associated with the combined trend in the $0-14$ and $60+$ population The regional diversity is very significant. In 1995, the ratio varied from 0.15 in the Far East Region to 0.37 in the Central Region. Differences are expected to remain. The value in 2025 is expected to vary between 0.26 and 0.38 in the Far East Region and between 0.42 and 0.50 in the Central Region. These regional differences will require differential policies on infrastructure and social security.

The most detailed information on aging is contained in the age pyramids. Figures 4-6 show the age pyramids of the population for Russia and two extreme cconomic-geographic regions in 1995 and the population in 2025 associated with the different scenarios. In the pessimistic scenarios the number of children decreases drastically (see, e.g., scenario PHA, which is characterized by high mortality, low fertility and relatively high immigration from other states of the former Soviet Union). The share of $60+$ population remains more or less at the current level up to 2005, but increases sharply afterward. The increase is exceptionally pronounced in the Far East, where the number of $60+$ more than doubles in the optimistic scenario.

A significant observation is the substantial increase in the net migration rates in the North Region, in East Siberia and the Far East Region in all scenarios except in the PHA scenario. The 
Table 1. Population of Russia and economic-geographic regions (in thousands), 1995-2025, different scenarios

\begin{tabular}{|c|c|c|c|c|}
\hline & 1995 & 2000 & 2010 & 2025 \\
\hline \multicolumn{5}{|l|}{ Scenario $O L C$} \\
\hline The Russian Federation & 147938.5 & 147054.3 & 147692.9 & 145757.1 \\
\hline The European part of Russia & 115991.0 & 115862.5 & 115972.9 & 112192.2 \\
\hline The North Region & 5958.2 & 5687.9 & 5673.1 & 6002.4 \\
\hline The North West Region & 8050.1 & 7817.5 & 7491.1 & 7072.7 \\
\hline The Central Region & 29825.4 & 29189.6 & 27992.6 & 25437.0 \\
\hline Volga-Vyatka region & 8480.7 & 8428.1 & 8328.6 & 7929.6 \\
\hline Central European Russia Region & 7871.2 & 7958.0 & 7996.0 & 7521.4 \\
\hline Volga Region & 16883.1 & 17187.8 & 17659.7 & 17372.8 \\
\hline North-Caucasus Region & 17548.2 & 18166.8 & 19328.6 & 20268.4 \\
\hline The Ural Region & 20447.7 & 20468.4 & 20513.9 & 19604.5 \\
\hline The Asian part of Russia & 31947.5 & 31191.9 & 31719.9 & 33564.8 \\
\hline West Siberian Region & 15148.8 & 15168.9 & 15331.5 & 14889.5 \\
\hline East Siberian Region & 9164.0 & 9024.8 & 9314.0 & 10041.7 \\
\hline Far East Region & 7634.7 & 6998.2 & 7074.4 & 8633.6 \\
\hline \multicolumn{5}{|l|}{ Scenario $O L B$} \\
\hline The Russian Fedcration & 147938.5 & 147054.3 & 147723.8 & 145858.5 \\
\hline The European part of Russia & 115991.0 & 115862.5 & 116536.8 & 114328.6 \\
\hline The North Region & 5958.2 & 5687.9 & 5526.4 & 5480.4 \\
\hline The North West Region & 8050.1 & 7817.5 & 7484.8 & 6993.3 \\
\hline The Central Region & 29825.4 & 29189.6 & 28150.8 & 26032.8 \\
\hline Volga-Vyatka region & 8480.7 & 8428.1 & 8407.8 & 8188.1 \\
\hline Central European Russia Region & 7871.2 & 7958.0 & 8064.5 & 7812.7 \\
\hline Volga Region & 16883.1 & 17187.8 & 17763.0 & 17782.6 \\
\hline North-Caucasus Region & 17548.2 & 18166.8 & 19451.5 & 20738.9 \\
\hline The Ural Region & 20447.7 & 20468.4 & 20692.5 & 20305.9 \\
\hline The Asian part of Russia & 31947.5 & 31191.9 & 31187,0 & 31529.9 \\
\hline West Siberian Region & 15148.8 & 15168.9 & 15378.1 & 15075.7 \\
\hline East Siberian Region & 9164.0 & 9024.8 & 9202.1 & 9567.2 \\
\hline Far East Region & 7634.7 & 6998.2 & 6606.8 & 6887.0 \\
\hline \multicolumn{5}{|l|}{ Scenario $M H C$} \\
\hline The Russian Federation & 147938.5 & 146391.1 & 142437.0 & 131880.0 \\
\hline The European part of Russia & 115991.0 & 115307.0 & 111849.3 & 101616.3 \\
\hline The North Region & 5958.2 & 5662.2 & 5451.7 & 5398.8 \\
\hline The North West Region & 8050.1 & 7776.4 & 7214.6 & 6391.3 \\
\hline The Central Region & 29825.4 & 29034.6 & 26972.5 & 23055.8 \\
\hline Volga-Vyatka region & 8480.7 & 8388.9 & 8031.2 & 7176.0 \\
\hline Central European Russia Region & 7871.2 & 7928.6 & 7763.7 & 6933.3 \\
\hline Volga Region & 16883.1 & 17113.4 & 17077.3 & 15820.0 \\
\hline North-Caucasus Region & 17548.2 & 18065.3 & 18587.3 & 18249.8 \\
\hline The Ural Region & 20447.7 & 20382.3 & 19788.0 & 17681.1 \\
\hline The Asian part of Russia & 31947.5 & 31084.1 & 30587.7 & 30263.7 \\
\hline West Siberian Region & 15148.8 & 15117.4 & 14852.5 & 13602.5 \\
\hline East Siberian Region & 9164.0 & 8974.4 & 8835.6 & 8722.4 \\
\hline Far East Region & 7634.7 & 6992.3 & 6899.6 & 7938.8 \\
\hline \multicolumn{5}{|l|}{ Scenario $M H B$} \\
\hline The Russian Federation & 147938.5 & 146391.1 & 142464.0 & 131974.3 \\
\hline The European part of Russia & 115991.0 & 115307.0 & 112395.9 & 103613.5 \\
\hline The North Region & 5958.2 & 5662.2 & 5309.3 & 4913.3 \\
\hline The North West Region & 8050.1 & 7776.4 & 7208.1 & 6315.3 \\
\hline The Central Region & 29825.4 & 29034.6 & 27126.3 & 23615.0 \\
\hline Volga-Vyatka region & 8480.7 & 8388.9 & 8108.1 & 7417.6 \\
\hline Central European Russia Region & 7871.2 & 7928.6 & 7830.2 & 7205.6 \\
\hline Volga Region & 16883.1 & 17113.4 & 17177.3 & 16201.1 \\
\hline North-Caucasus Region & 17548.2 & 18065.3 & 18706.6 & 18690.5 \\
\hline The Ural Region & 20447.7 & 20382.3 & 19961.2 & 18335.2 \\
\hline The Asian part of Russia & 31947.5 & 31084.1 & 30068.1 & 28360.8 \\
\hline
\end{tabular}


Table 1. - Continued.

\begin{tabular}{|c|c|c|c|c|}
\hline & 1995 & 2000 & 2010 & 2025 \\
\hline \multicolumn{5}{|l|}{ Scenario MIIB } \\
\hline West Siberian Region & 15148.8 & 15117.4 & 14897.0 & 13771.3 \\
\hline East Siberian Region & 9164.0 & 8974.4 & 8727.2 & 8284.6 \\
\hline Far East Region & 7634.7 & 6992.3 & 6443.9 & 6304.8 \\
\hline \multicolumn{5}{|l|}{ Scenario PHA } \\
\hline The Russian Federation & 147938.5 & 145515.7 & 136680.4 & 115453.2 \\
\hline The Europcan part of Russia & 115991.0 & 114536.7 & 108229.5 & 92378.3 \\
\hline The North Region & 5958.2 & 5620.7 & 4914.0 & 3763.4 \\
\hline The North West Region & 8050.1 & 7726.8 & 6915.0 & 5423.8 \\
\hline The Central Region & 29825.4 & 28886.6 & 26344.6 & 21461.9 \\
\hline Volga-Vyatka region & 8480.7 & 8329.6 & 7821.1 & 6672.1 \\
\hline Central European Russia Region & 7871.2 & 7876.9 & 7584.0 & 6613.2 \\
\hline Volga Region & 16883.1 & 16998.6 & 16558.6 & 14557.5 \\
\hline North-Caucasus Region & 17548.2 & 17899.6 & 17862.1 & 16483.7 \\
\hline The Ural Region & 20447.7 & 20248.0 & 19292.3 & 16588.6 \\
\hline The Asian part of Russia & 31947.5 & 30979.1 & 28450.9 & 23074.9 \\
\hline West Siberian Region & 15148.8 & 15030.2 & 14378.5 & 12273.1 \\
\hline East Siberian Region & 9164.0 & 8909.1 & 8216.8 & 6713.7 \\
\hline Far East Region & 7634.7 & 7039.8 & 5855.6 & 4088.2 \\
\hline
\end{tabular}

pattern is consistent with the assumed change in net migration: the PHA scenario is the only one with a stable internal migration pattern, i.e. a pattern that is characterized by a continued outmigrations from these regions. The high mobility pattern (C) and, to a lesser extent, the medium pattern (B), signify a turnaround of net migration for these regions to compensate for the population losses in the years after 1992. In the PHA scenario, the Far East loses close to 100,000 people every year up to the year 2000 and loses more than 70,000 every year during the following five years; the losses diminish afterward but they still reach 44,000 every year during 2020-2024. In the most optimistic scenario (high mobility), the Far East becomes a region with low outmigrations and substantial immigration, and gains 126,000 migrants every year during 2020-2024. As a consequence, its share in the population of Russia increascs from $5.2 \%$ in 1995 to $6.0 \%$ in 2025 .

\section{(c) Comparison to other projections}

Since the projections presented in this article were performed at the level of oblast it makes sense to compare the results of our calculations with the projections performed at the same level of detail. To our knowledge only the official projections made by State Committee on Statistics qualify for such comparison (Goskomstat of Russia, 1996). This projection uses similar baseline data. Population is projected by age, sex, urban and rural areas until the year 2010 .
Three scenarios are distinguished:

Medium: Slow recovery from socioeconomic crisis. Starting from the year 2000 shifts toward mortality decline and the level of fertility corresponds to reproductive intensions recorded by 1994.

Pessimistic: Socioeconomic crisis continues. Mortality trends are extrapolated from 1965-80. Fertility stabilizes at a very low level (the limit values are similar to ours).

Optimistic: Fast recovery from the crises. Mortality declines in the nearest future and fertility returns to its pre-crisis level.

One can easily observe that fertility and mortality assumptions incorporated in medium, pessimistic and optimistic scenarios are very similar to ours. This is not a coincidence. The same group of experts was involved in preparation of assumptions for both projections. Thus fertility and mortality assumptions are also very similar on the regional level.

Goskomstat, however, produces only one scenario for internal and international migration. For internal migration the major assumption is that North, Ural and East Siberian Regions always have an outflow of migrants. By 2000 the outflow will exceed 300,000 people. Later this outflow slows down only because migration potential is exhausted. Migrants from these regions are mainly aimed at the Central, NorthCaucasian, Volga and Central European Russian Regions.

International net migration is always positive within the projection period and almost linearly 
declines from 500,000 people in 1995 to 180,000 in 2000 and later more slowly to 75,000 in 2010 .

Different migration assumptions complicate the comparison between Goskomstat and our projections. Another difficulty is that we made projections for five-year age groups and thus a projection step was equal to five years. Popula- tion size in our projections corresponds to the beginning of the year. Goskomstat gives results for the end of the year and for 2000, 2005 and 2010 only. Total population of the country (in thousands) is available for each year, thus allowing for comparison with our projections (see Table 2).

\section{Russia, 1995}

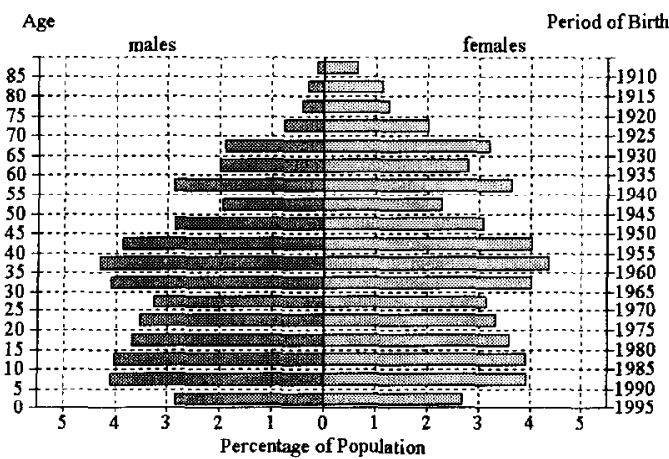

Russia, 2025

Scenario OLB

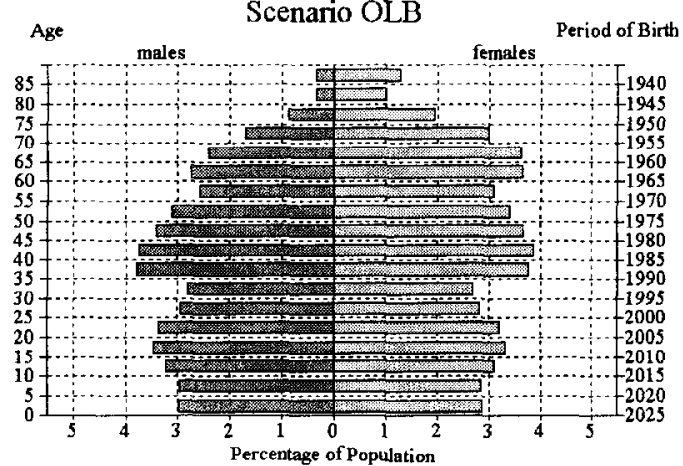

Russia, 2025

Scenario MHB

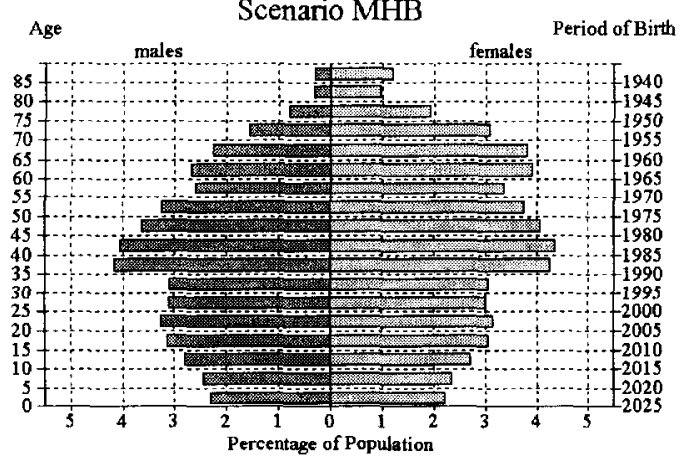

Russia, 2025

Scenario OLC

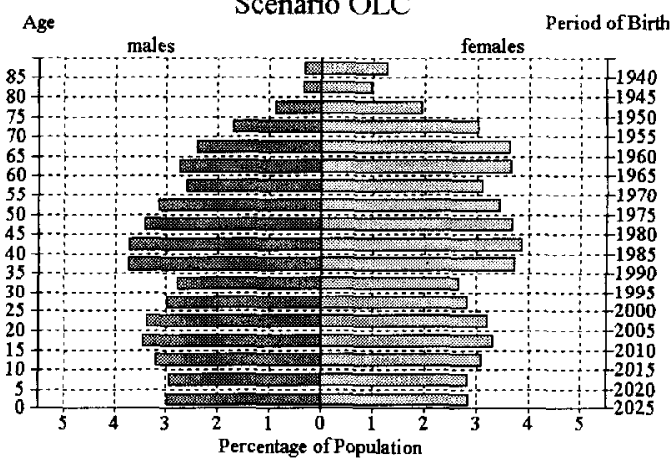

Russia, 2025

Scenario MHC

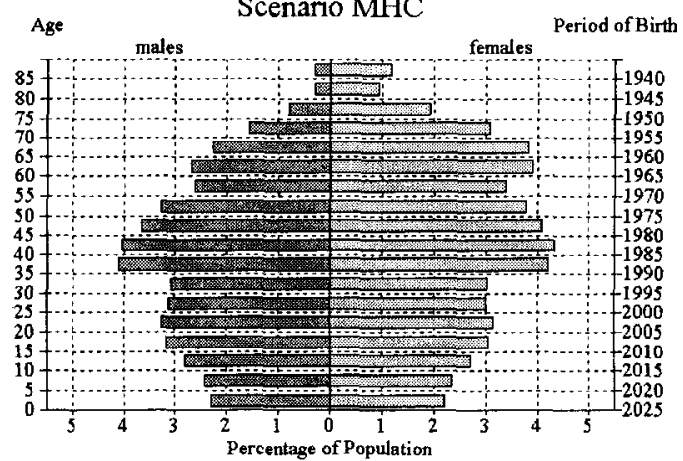

Russia, 2025

Scenario PHA

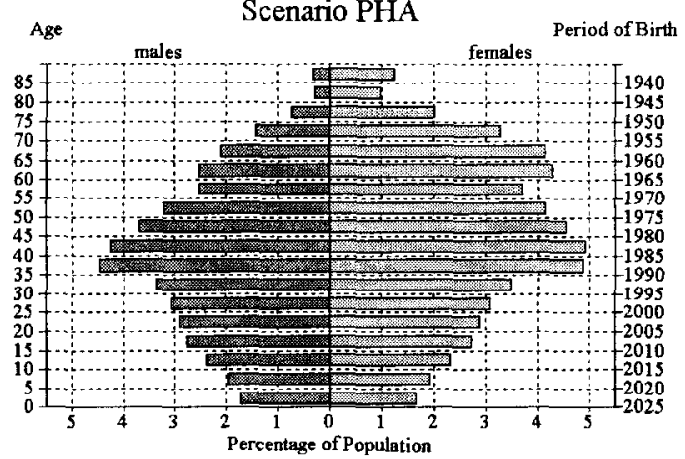

Figure 4. Population age pyramid of Russia, 1995 and 2025: different scenarios. 
At the country level, the internal migration scenario has very little influence on the total population size (total population size is practically equal for scenarios OLC and OLB, MHC and MHB). This gives us an opportunity to compare our OLB, MHB and PHA scenarios with Goskomstat's Medium, Pessimistic and
Optimistic scenarios correspondingly. Since Goskomstat assumed a more rapid decline of external net migration, our projections produce slightly higher total population numbers (see Table 1).

Even on the regional level we do not observe the striking differences in population distribu-
The Central Region, 1995

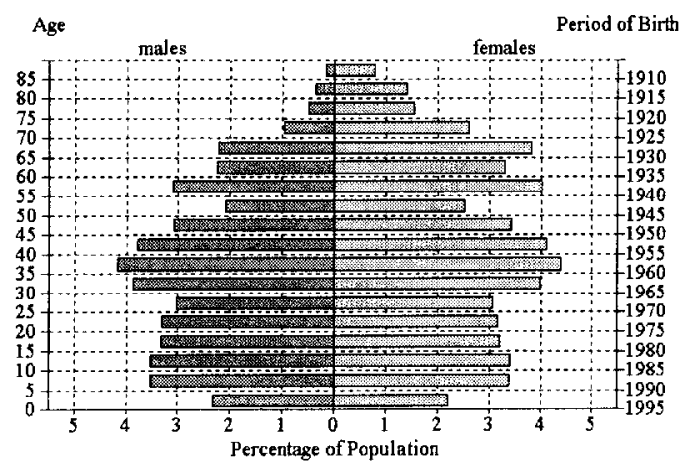

The Central Region, 2025

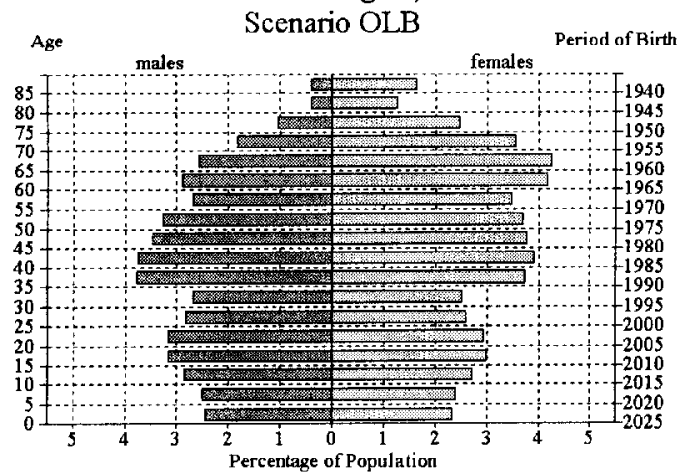

The Central Region, 2025

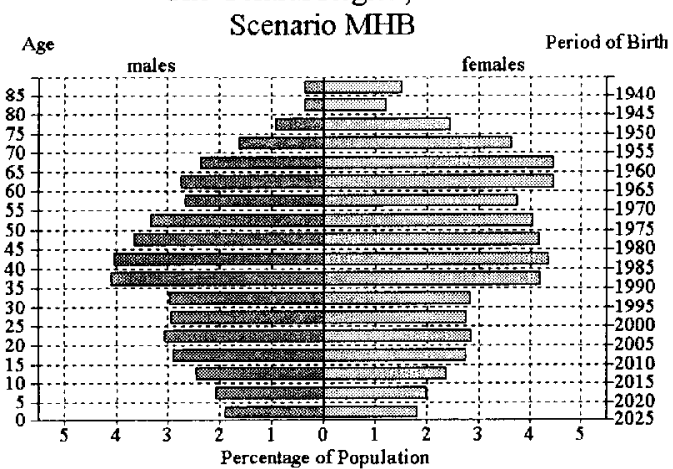

The Central Region, 2025 Scenario OLC

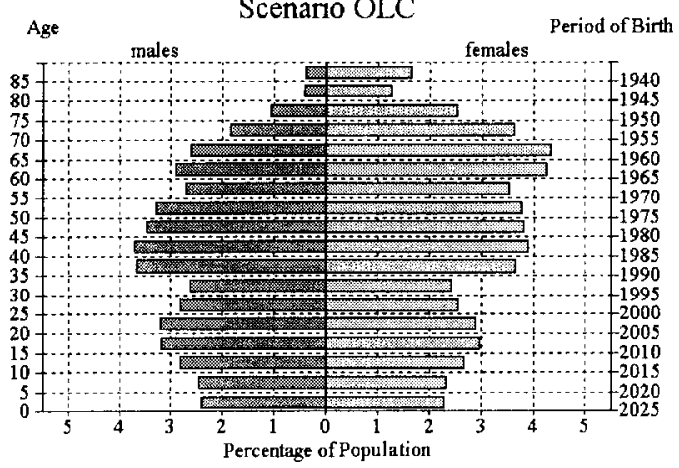

The Central Region, 2025 Scenario MHC

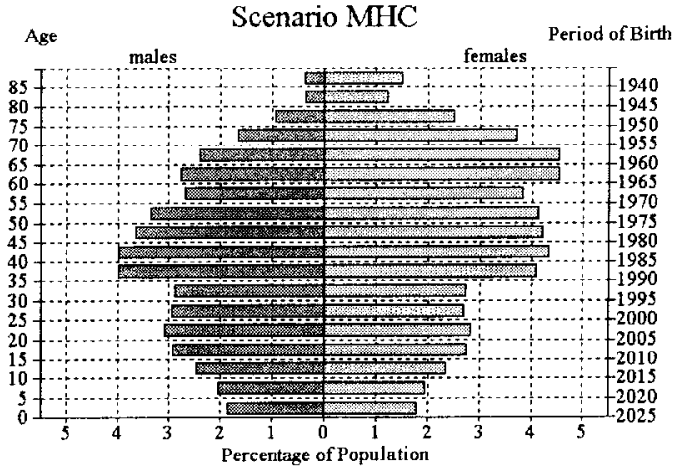

The Central Region, 2025

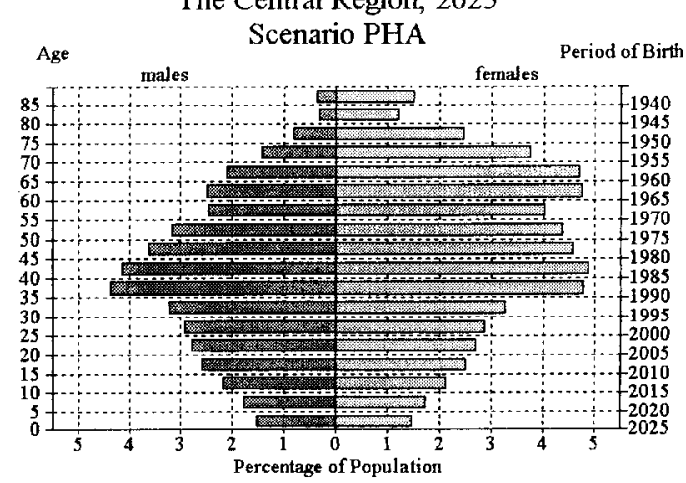

Figure 5. Population age pyramid of the Central Region, 1995 and 2025: different scenarios. 
tions. This may be explained by the fact that the main changes in migration flows in our scenarios which end with the letters $\mathrm{C}$ and $\mathrm{B}$ occur after the year 2005 (e.g., reverse of migration flows to North or Far East Regions). But, scenarios
MHC and OLC show more similarity to Medium and Optimistic scenarios of Goskomstat than scenarios MHB and OLB (see Table 3). In Table 3 we present the relative difference in regional population size between our and Goscomstat
Far East Region, 1995

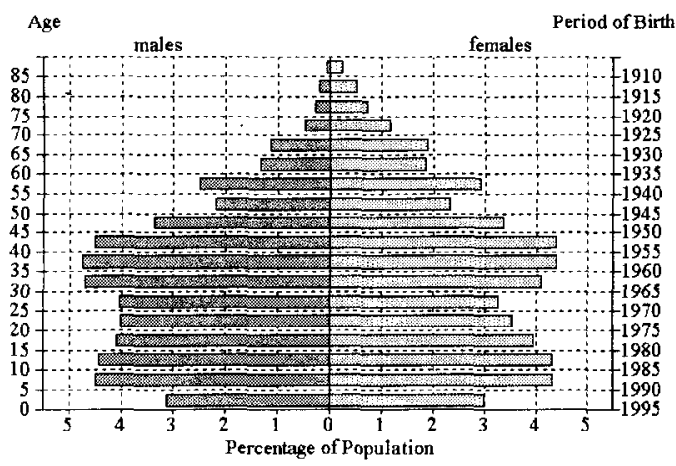

Far East Region, 2025 Scenario OLB

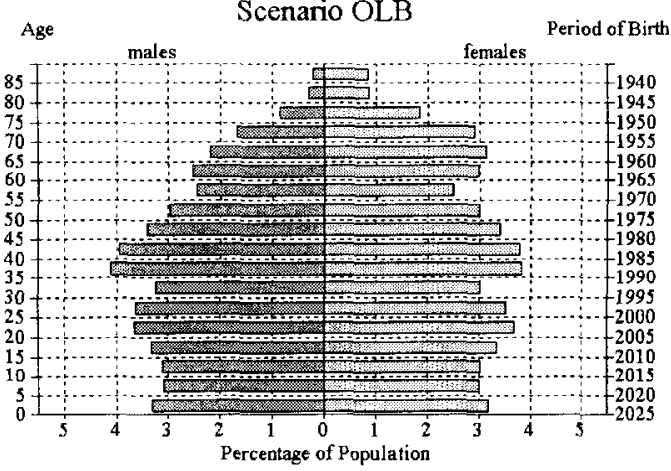

Far East Region, 2025 Scenario MHB

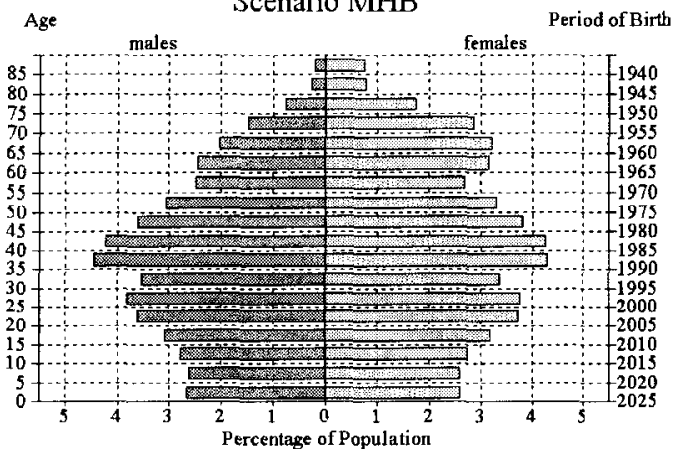

Far East Region, 2025 Scenario OLC

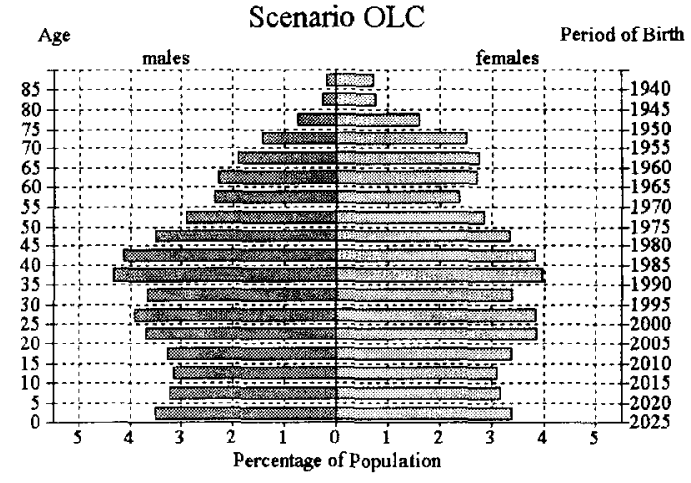

Far East Region, 2025 Scenario MHC

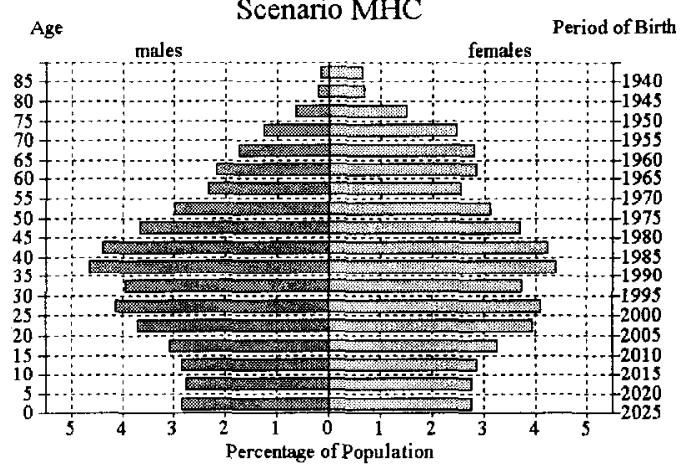

Far East Region, 2025 Scenario PHA

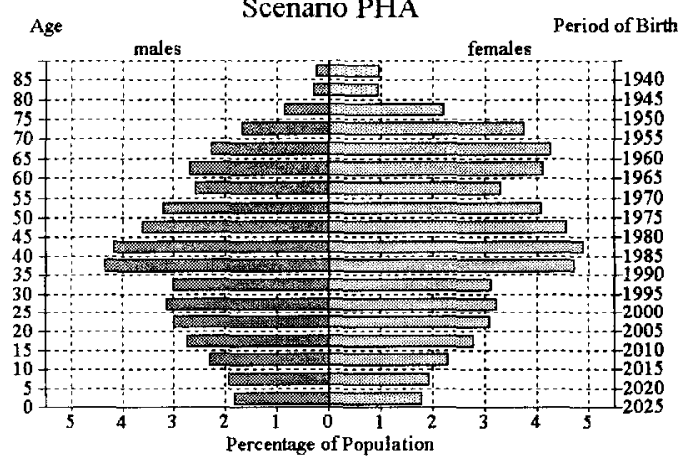

Figure 6. Population age pyramid of the Far East Region, 1995 and 2025: different scenarios. 
Table 2. Total population, 1995-2009 (in thousands)

\begin{tabular}{lccc}
\hline Year & Medium & Pessimistic & Optimistic \\
\hline 1995 & 147,609 & 147,609 & 147,609 \\
1999 & 145,951 & 145,150 & 146,588 \\
2004 & 143,461 & 140,464 & 146,488 \\
2009 & 140.866 & 134,897 & 147,381 \\
\hline
\end{tabular}

scenarios. Data correspond to 2010. Keep in mind that Goskomstat data correspond to the end of the year and ours to the beginning.

As we see from Table 3 the biggest difference between Goskomstat and our projections is observed in Far East Region. Obviously, our migration assumptions for the forthcoming 10-15 years suggest a bigger outflow of migrants from Far East Region then those projected by Goskomstat.

\section{CONCLUSION AND POLICY IMPLICATIONS}

Russia has a shrinking population. During 1995-2025, the number of people is expected to decline by two million in the optimistic scenario and 32 million in the pessimistic scenario. Low fertility is the major reason for the decline. If future fertility occurs according to the expectations revealed by women in the 1994 MicroCensus, and mortality change would not be much different from what it has been over the past years, the population in 2025 would be 28 million less than the 148 million today. In 2025 , Russia is expected to have from 20 to more than $50 \%$ fewer children than today, depending on the scenario. The decline in the population of working age is expected to be between 14 and $25 \%$. The size of the elderly $(60+)$ population increases, however. In 1995, 22 million people were aged $60+$; in 2025 the number is expected to be between 22 and 28 million. Most of the increase takes place after 2010.

The spatial redistribution of the population of Russia, which was initiated during recent years, is expected to continue. The general trend is a redistribution from the North and East (East Siberia and Far East) to the European Part of Russia, in particular the southern regions of the European part (North Caucasus and Volga Regions). Whether the very high outmigration from the Far East continues, ubserved during recent years, remains uncertain. The scenarios express that uncertainty. The Far East is likely to lose population, unless there is a substantial migration turnaround, in which case the share of the Far East in the population of Russia increases slightly.

Notwithstanding the uncertainty inherent in any population projection, the demographic development of Russia will be a major challenge to policy makers in the 21 st century. A country with vast resources and a shrinking population may need to attract both foreign investment and foreign labor to maintain adequate economic growth. In the future, Russia may need not only technology, but also labor. That fact, combined with the ongoing redistribution of the Russian population from the North and East to the European Part of Russia, may lead to a situation

Table 3. Relative differences in regional population

\begin{tabular}{lrrrrr}
\hline & $\begin{array}{c}\text { Medium } \\
\text { vs. MHC }\end{array}$ & $\begin{array}{c}\text { Pessimistic } \\
\text { vs. PHA }\end{array}$ & $\begin{array}{c}\text { Optimistic } \\
\text { vs. OLC }\end{array}$ & $\begin{array}{r}\text { Medium } \\
\text { vs. MHB }\end{array}$ & $\begin{array}{r}\text { Optimistic } \\
\text { vs. OLB }\end{array}$ \\
\hline The Russian Federation & 1.51 & 2.30 & 0.09 & 1.53 & 0.11 \\
The North Region & 1.84 & -3.00 & 0.32 & -0.82 & -2.27 \\
The North West Region & -1.26 & -0.73 & -2.73 & -1.35 & -2.81 \\
The Central Region & 0.75 & 2.48 & -0.48 & 1.32 & 0.08 \\
Volga-Vyatka region & 1.88 & 4.41 & 0.87 & 2.86 & 1.83 \\
Central European Russia Region & 3.59 & 6.11 & 2.17 & 4.47 & 3.05 \\
Volga Region & 3.39 & 5.33 & 2.13 & 3.99 & 2.73 \\
North-Caucasus Region & 1.31 & 3.41 & 0.32 & 1.96 & 0.96 \\
The Ural Region & 2.39 & 4.91 & 0.93 & 3.28 & 1.81 \\
West Siberian Region & 1.97 & 3.17 & -0.07 & 2.27 & 0.24 \\
East Siberian Region & 0.09 & -1.83 & -1.37 & -1.14 & -2.55 \\
Far East Region & -1.76 & -12.34 & -4.17 & -8.25 & -10.50 \\
\hline
\end{tabular}


in which the development of large parts of Siberia is dependent on "New Russians" or migrant labor. Russia has the advantage that it can learn from the experiences of countries in the Middle East, North America, and Europe. Depending on the speed of development of Siberia, the population composition may change significantly.

Even with substantial immigration, the greying of Russia will continue. Given that the economic base for a comprehensive social security program will be lacking for decades, the elderly will need to manage (e.g., work longer) and will continue to depend on their children for financial support. Given the health status of the elderly, an increase in the age at retirement may not be an option. The family remains the best social security program Russia has and will have for years to come. Policy makers should cherish the family as the basic unit of social and economic support, and avoid the road of excessive individualization that some countries in the West have followed. At the same time, a social security policy should be developed alongside an economic growth policy to assure harmonious development into the 21 st century.

\section{NOTES}

1. As part of the scenario study, the recent demographic trends in Russia were analyzed thoroughly. The results of the investigation are reported elsewhere (Volkov et al, forthcoming).

2. It was Lenin's view that the country could only be held together when the different peoples had some autonomy.

3. The model being used is described by Pobedina (1966).

4. The value of the intercept is determined such that the life expectancy estimated from the survival probabilities predicted by the model is equal to the observed life expectancy.

5. The migration efficiency is the ratio between the net migration and the sum of immigration and outmigration (see Andreev, forthcoming). The migration efficiency was $8 \%$ in $1989,17 \%$ in $1990,10 \%$ in 1991 and jumped to $48 \%$ in 1994 .

6. Most of the balance is related to migration from the other states of the former Soviet Union. The migration balance with the states of the former Soviet Union was 914,000 in 1994 and 612,000 in 1995.

7. During 1990-94, the life expectancy of males declined more than six years (from 63.8 to 57.6 ). In some regions, the decline was much more rapid. For instance, in the Republic of Karelia, which borders Finland, the life expectancy of males declined from 63.7 in $1989-90$ to 54.9 in 1994. During the same period, the life expectancy of women declined from 74.5 to 69.0 .

8. The age pyramid of some regions (e.g., Perm, included in North) shows a near absence of males at ages $70+$.

9. The retirement age is 60 for males and 55 for females. The Demographic Yearbook publishes the share of the old-age dependent population: males $60+$ and females 55+. Today, many women and men work beyond retirement age. A recent law permits the combination of pension and income from work.

10. In 1994, the lowest life expectancy was recorded in Tuva (48.9 for males and 62.9 for females); the highest life expectancy was in Dagestan (65.5 for males and 75.0 for females).

11. The TFR of the Chechen Republic is not given in The Demographic Yearbook. Until January 1, 1994, the Chechen and Ingush republics were combined. It is likely that the figure for Chechen docs not differ much from the TFR in Ingush Republic, which was 2.9 in 1989-90 and is currently estimated at 2.7 .

\section{REFERENCES}

Andreev, E. (forthcoming) Mortality. In Demographic Scenarios for Russia by Area, ed. A. Volkov et al.

Andreev, E., Scherbov, S. and Willekens, F. (1997) The Population of Russia: Fewer and Older. Demographic Scenarios for Russia and its Regions. Demographic Reports, Faculty of Spatial Sciences, University of Groningen, The Netherlands.

Bondarskaya, G.A. and Darsky, L.E. (forthcoming) Fertility and nuptiality. In Demographic Scenarios for Russia by Area, ed. A. Volkov et al.

Centre for Economic Conjuncture (1994) Population Projections up to 2005. Centre for Economic Conjuncture, Moscow [in Russian].
Guskumslat of Russia (1996) The Demugraphic Yearbook of Russia. Statistical Handbook. State Committee of the Russian Federation on Statistics, Moscow.

Pobedina, A.P. (1966) Perspective computer calculations of population. In Problems of Population and Demographic Statistics, pp. 377-387. Statistika, Moscow [in Russian].

Volkov, A. et al., eds. (forthcoming) Demographic scenarios for Russia by Area.

Zaianclikovskaya, Z. (1994) Migration in Russia after dissolution of the USSR. Population and Society, No. 1 [in Russian]. 